\title{
New Evidence for the Psychometric Properties of the Spanish Version of the Gain in Alzheimer Care Instrument
}

\author{
F. Javier García-Castro ${ }^{1}$ D, F. Pablo Holgado-Tello ${ }^{2}$ iD and María J. Blanca $^{1}$ (D) \\ ${ }^{1}$ Universidad de Málaga (Spain) \\ ${ }^{2}$ Universidad Nacional de Educación a Distancia (Spain)
}

\begin{abstract}
The aim was to analyze the psychometric properties of the Spanish version of the Gain in Alzheimer Care Instrument (GAIN), providing validity evidence based on its internal structure, reliability, item analysis, and relationships with other variables. A sample of 113 informal caregivers of people with dementia completed the GAIN, along with questionnaires assessing burden, general mental health, stress, anxiety, depression, and life satisfaction. Confirmatory factor analysis showed a single-factor structure with adequate fit indices. Reliability of GAIN scores was satisfactory, with McDonald's omega equal to .91. Items yielded adequate homogeneity indices. Validity evidence based on relationships with other variables was provided by positive correlations between GAIN scores and life satisfaction, and negative correlations with burden, general mental health problems, stress, anxiety, and depression. All these correlations were statistically significant, and most of them were of moderate magnitude. The Spanish version of the GAIN has a single-factor structure and satisfactory psychometric properties. It is quick and easy to apply and given the association between GAIN scores and other variables, it may be used to provide information about a caregiver's psychological health status.
\end{abstract}

Received 10 December 2020; Revised 6 April 2021; Accepted 14 April 2021

Keywords: Alzheimer care, confirmatory factor analysis, positive aspects of caregiving, single-factor structure

An informal caregiver is someone who provides unpaid care to another person, normally a family member or friend, who requires help due to physical or mental ill health, disability or problems associated with old age (Fowler, 2015; Settineri et al., 2014). Studies of informal caregivers of people with dementia have demonstrated that this role can have a number of negative consequences, including burden, depression, anxiety, stress, irritability, poorer wellbeing and health, sleep disturbances, social isolation, and an increased risk of cardiovascular disease (Del-Pino-Casado \& Ordóñez-Urbano, 2016; Fowler, 2015; Pearlin et al., 1990; Roepke et al., 2012; Zarit et al., 1980). However, a smaller body of research suggests that being a caregiver can also bring some positive benefits (Kramer, 1997a; Rapp \& Chao,

Correspondence concerning this article should be addressed to F. Javier García-Castro. Universidad de Málaga. Departamento de Psicobiología y Metodología de las Ciencias del Comportamiento.

E-mail: fergarde@uma.es

We thank the day centers for people with Alzheimer's disease and other dementias in Málaga for their help in recruiting participants for this study.

Funding Statement: This research received no specific grant from any funding agency, commercial or not-for-profit sectors.

Conflicts of Interest: None.
2000). Rapp and Chao (2000), for instance, found that some informal caregivers reported a sense of personal growth and satisfaction, the learning of new skills, and an improved relationship with the care recipient and/or with others. Similarly, Cohen et al. (2002) noted that most caregivers were able to identify at least one positive aspect of their role, the most commonly cited being companionship, feelings of satisfaction and reward, fulfillment, and a sense of duty. These authors also found that positive feelings about caregiving were negatively associated with caregiver burden and depression.

Kramer (1997a) used the term gain to refer to any positive benefit resulting from the caregiving role and went on to show (Kramer, 1997b) that such gains were negatively predicted by level of education and positively predicted by problem-focused coping and satisfaction with social life. Sanders (2005) subsequently proposed three main kinds of gain: (a) Spiritual growth

How to cite this article:

García-Castro, F. J., Holgado-Tello, F. P., \& Blanca, M. J. (2021). New evidence for the psychometric properties of the spanish version of the gain in alzheimer care instrument. The Spanish Journal of Psychology, 24. e32. Doi:10.1017/SJP.2021.32 
and increased faith, described by caregivers as a deepened sense of spirituality or a closer relationship to God; (b) personal growth, such as becoming more patient or mature; and (c) feelings of mastery and accomplishments, associated with the perception of having been successful in the role of caregiver. In a similar vein, Netto et al. (2009) also proposed three kinds of gain: (a) Personal growth, related to increased patience and understanding and a sense of mastery and of having acquired new skills and personal qualities such as resilience or humility; (b) gains in relationships, in the sense of an improved relationship with the care recipient and an increased ability to relate to other older adults; and (c) higher-level gains, such as spiritual growth.

Based on the latter three categories, Yap et al. (2010) developed the Gain in Alzheimer Care Instrument (GAIN) to measure the benefits of caring for a person with dementia. This instrument comprises 10 items, the first four of which refer to personal growth, the following three to gains in relationships, and the final three to higher-level gains. The authors performed an exploratory factor analysis (EFA) and principal components analysis (PCA) and concluded that the GAIN had a unidimensional structure. They also examined correlations between GAIN scores and caregiver burden (measured with the Zarit Burden Interview, ZBI), dementia management strategies (evaluated using the Dementia Management Strategies Scale, DMSS), and positive aspects of caregiving (Positive Aspects of Caregiving scale). This analysis showed that GAIN scores were negatively correlated with burden (ZBI) and criticism (DMSS), and positively correlated with positive aspects of caring and with encouragement (DMSS) and active management (DMSS).

Liew et al. (2010) explored the relationship between caregiving gains and both caregiver and care recipient variables. They found that higher GAIN scores were obtained by caregivers who were not in work, who had been the caregiver for more than three years, who spent at least $60 \%$ of their time each week on caregiving tasks, who had daily contact with the care recipient, who had minimal or no financial difficulties, who attended caregiver educational and support programs, and who cared for a person with a more advanced stage of dementia. These authors also examined correlations between GAIN scores and feelings of competence in the caregiver (measured using the Short Sense of Competence Questionnaire, SSCQ), dementia management strategies (evaluated with the DMSS), caregiver burden (ZBI), general mental health problems in the caregiver (assessed using the General Health Questionnaire 28, GHQ-28), and behavior problems in the care recipient (assessed with the Revised Memory and Behavior Problems Checklist, RMBPC). They found that GAIN scores were positively associated with the caregiver's sense of competence (SSCQ) and with the use of encouragement and active management strategies (DMSS), and negatively correlated with burden (ZBI), mental health problems in the caregiver (GHQ-28), criticism as a management strategy (DMSS), and behavior problems in the care recipient (RMBPC). Regression analysis also showed that active management as a caregiving strategy, mental wellbeing of the caregiver, and participation in educational and support programs were significantly associated with gains, with the strongest predictor being an active management strategy.

Fabà and Villar (2013) adapted the GAIN for use in the Spanish population. They analyzed its internal structure by means of EFA and concluded that the Spanish version replicated the single-factor structure of the original instrument. Reliability was assessed using the split-half method and by calculating Cronbach's alpha coefficient $(\alpha=.87)$. Item homogeneity indices ranged between .46 and .68 , and internal consistency was not significantly improved by omitting any of the items. Although the authors also sought to provide validity evidence based on relationships with other variables, this was only explored with respect to sociodemographic variables (age, gender, level of education, marital status, religiosity, caregiver's perceived health, relationship to the care recipient, time spent as the caregiver, and hours per day and days per week dedicated to the caregiving role), of which only religiosity was significantly associated (in this case, positively) with GAIN scores. More recently, and with the aim of measuring more potential gains than are considered by the GAIN, Fabà et al. (2017) developed the 22-item Gain Associated with Caregiving (GAC) scale. However, they did not obtain sufficient evidence of validity based on internal structure, since neither the single-factor model nor multi-factor models showed a good fit to the data. Furthermore, the GAC scale is focused on the Spanish population and it has not been adapted for use in other languages or countries, thus preventing crosscultural comparisons. Consequently, our analysis here is focused on the GAIN, an instrument that is widely and internationally used.

Despite the important contribution of Fabà and Villar's (2013) study, the internal structure of the Spanish version of the GAIN has yet to be examined by means of confirmatory factor analysis (CFA), and validity evidence based on its relationships with psychological variables is still lacking. In order to address this gap, our aim here was to analyze the psychometric properties of the GAIN in a sample of Spanish informal caregivers of people with dementia. Specifically, we sought, first, to provide new validity evidence based on the internal structure of the instrument, using CFA to test the single-factor structure reported previously. Second, we analyzed the reliability of GAIN scores and 
examined item homogeneity. Finally, we aimed to provide new validity evidence based on relationships with other variables. The specific variables we considered were burden and mental wellbeing of the caregiver, which were explored when validating the original instrument (Liew et al., 2010; Yap et al., 2010) but not the Spanish version, and stress, anxiety, depression, and life satisfaction, which have yet to be examined in relation to GAIN scores. We expected to find that GAIN scores were positively associated with life satisfaction and negatively associated with caregiver burden, general mental health problems, stress, anxiety, and depression.

\section{Materials and Methods}

\section{Participants}

The initial sample comprised 115 informal caregivers of people diagnosed with dementia, of whom 113 (25 male and 88 female) were included in the final analysis. The exclusion of two participants was due to missing values in GAIN scores. As these cases accounted for less than $5 \%$ of the total, we opted to analyze only those cases with complete data (Garson, 2015). The informal caregivers ranged in age from 35 to 82 years $(M=56, S D=$ 12.94) and they were recruited through 11 different day centers for people with Alzheimer's disease and other dementias in the province of Malaga (Spain). To be eligible for participation they had to be over 18, to have spent at least six months as the caregiver of a person with dementia, to have a command of Spanish sufficient for understanding and answering the questionnaires, and to sign informed consent. In addition, the care recipient in each case had to have been diagnosed with dementia and to be attending one of the 11 aforementioned centers. The majority of caregivers were Spanish $(97.35 \%)$, married $(71.68 \%)$, lived with the care recipient $(78.76 \%)$, and were his/her son or daughter (66.37\%). Approximately half of the caregivers were in employment $(43.36 \%)$ and a similar proportion $(40.71 \%)$ had either no or only elementary school education. The time spent as a caregiver ranged from 1 year to eight years $(M$ $=4.81$ years, $S D=3.80$ ).

\section{Instruments}

\section{Caregiver gains}

Gains were assessed with the Gain in Alzheimer Care Instrument (GAIN; Yap et al., 2010), in its Spanish version (Fabà \& Villar, 2013; APA 2015). This is a 10-item scale with a five-point Likert-type response format $(0=$ disagree a lot, $4=$ agree a lot $)$, and higher total scores indicate a higher level of perceived gains.
Exploratory factor analysis has shown that both the Spanish and the original version have a single-factor structure.

\section{Caregiver Burden}

Caregiver burden was assessed using the Spanish version (Martín et al., 1996) of the Zarit Burden Interview (ZBI; Zarit et al., 1980). This self-report scale comprises 22 items (e.g., Do you feel that your relative asks for more help than he/she needs?) that are rated using a five-point Likert-type scale $(1=$ never; $5=$ almost always $)$. A higher total score indicates a greater level of perceived burden. Cronbach's alpha in the present sample was .94.

\section{General Mental Health}

The general mental health of caregivers was assessed using the Spanish version (Rocha et al., 2011) of the General Health Questionnaire 12 (GHQ-12; Goldberg \& Williams, 1988). The GHQ-12 is a unidimensional questionnaire used to screen for psychiatric problems, and each of its 12 items is rated on a four-point Likerttype scale ('less than usual', 'no more than usual', rather more than usual, and 'much more than usual'). Because the GHQ-12 comprises both positive and negatively worded items (e.g., Have you recently been able to face up to your problems? Have you recently been feeling unhappy and depressed?), these response options are arranged so that no reverse scoring is necessary, and consequently higher total scores indicate poorer mental health. Cronbach's alpha coefficient in the present sample was .90 .

\section{Depression, Anxiety, and Stress}

The Spanish version (Daza et al., 2002) of the Depression Anxiety Stress Scales (DASS-21; Lovibond \& Lovibond, 1995a, 1995b) comprises 21 items distributed equally across three subscales, corresponding to depression, anxiety, and stress. Each item is rated on a four-point Likert-type scale (from $0=$ did not apply to me at all, to $3=$ applied to me very much or most of the time; the time frame for responses is the past week), and higher scores on each subscale indicate a higher level of the respective variable. Example items are: I couldn't seem to experience any positive feeling at all (depression), I experienced breathing difficulty (anxiety), and I found it difficult to relax (stress). Cronbach's alpha coefficients in the present sample were $.87, .85$, and .88 for the depression, anxiety, and stress subscales, respectively.

\section{Life Satisfaction}

Life satisfaction was measured with the Spanish version (Vázquez et al., 2013) of the Satisfaction With Life Scale (SWLS; Diener et al., 1985). This is a unidimensional instrument and each of its five items (e.g., In most ways 
my life is close to my ideal) is rated on a seven-point Likerttype scale $(1=$ strongly disagree; 7 = strongly agree $)$. Higher total scores indicate a higher level of life satisfaction. Cronbach's alpha coefficient in the present sample was .88 .

\section{Procedure}

We began by contacting the managers of various day centers for people with Alzheimer's disease and other dementias in the province of Malaga, informing them about the study objectives and procedures. In those day centers that agreed to participate, the caregivers of center users were informed by managers about the study and invited to take part. Those who agreed and who signed informed consent for anonymized data collection and analysis were then given the aforementioned questionnaires to complete. The study was carried out in accordance with the Declaration of Helsinki and it was approved by the Experimentation Ethics Committee of the University of Malaga.

\section{Data Analysis}

We first conducted a descriptive analysis of GAIN item scores, calculating the mean, the standard deviation, and skewness and kurtosis coefficients.

In order to obtain validity evidence based on the internal structure of the GAIN we performed a CFA, testing a single-factor model using EQS 6.4 (Bentler, 2006). Because GAIN items are scored using a Likerttype scale, the analysis was based on the polychoric correlation matrix, using robust maximum likelihood estimators. We computed the Satorra-Bentler chi-square $\left(\mathrm{S}-\mathrm{B} \chi^{2}\right)$, along with the following goodness-of-fit indices (Bentler, 2006): The comparative fit index (CFI; Bentler, 1990), the non-normed fit index (NNFI; Bentler \& Bonett, 1980), and the root mean square error of approximation (RMSEA; Browne \& Cudeck, 1993; Steiger, 2000). Values of the CFI and the NNFI approaching .95 indicate an acceptable fit (Bentler, 1992; Bentler \& Bonett, 1980; Hu \& Bentler, 1999; McDonald \& Ho, 2002), while a value of .95 or higher indicates good fit (Hu \& Bentler, 1999); RMSEA values above .08 indicate poor model fit, those between .06 and .08 a reasonable fit (Browne \& Cudeck, 1993; MacCallum et al., 1996), and those below .06 a good fit (Hu \& Bentler, 1999).

The reliability of test scores was examined by calculating McDonald's omega coefficient. Values of .70 or higher are considered acceptable (Campo-Arias \& Oviedo, 2008; Ventura-León \& Caycho-Rodríguez, 2017; Viladrich et al., 2017).

For the item analysis we computed corrected itemtotal correlation coefficients, which indicate the correlation between a given item and the total test score when that item is omitted. Values above .30 are considered satisfactory (De Vaus, 2002; Traub, 1994).

We also analyzed the relationship between GAIN scores and other variables by calculating Pearson correlation coefficients, which we interpreted according to Cohen's (1988) criteria: Around |.10| indicates a small correlation, around $|.30|$ a moderate correlation, and |.50| or higher a strong correlation. The other variables considered here were caregiver burden, general mental health problems, stress, anxiety, depression, and life satisfaction.

Finally, having confirmed that the instrument has adequate psychometric properties, we calculated the mean and standard deviation for GAIN scores in the present sample of informal caregivers. All these analyses were performed using IBM SPSS.

\section{Results}

\section{Descriptive Item Analysis}

Table 1 shows the descriptive analysis of item scores. Most of the skewness and kurtosis indices indicate deviations from the normal curve, which justifies the use of the robust maximum likelihood method for the CFA.

\section{Validity Evidence Based on Internal Structure}

The fit indices for the single-factor model of the GAIN (Table 2) indicated satisfactory (CFI and NNFI) and reasonable (RMSEA) model fit. Although the upper bound of the confidence interval for the RMSEA was above .08 , this may be an estimation error caused by the small sample size. At all events, and as Jöreskog and Sörbom (2003) recommend, the fit of a model should be decided on the basis of the goodness-of-fit indices as a whole. Consequently, and given the values obtained, we found no reason to reject the hypothesis that the model reproduces the sample covariance matrix. The standardized coefficients are shown in Figure 1, and they are all statistically significant.

\section{Reliability and Item Analysis}

The value obtained for McDonald's omega coefficient was .91, which indicates satisfactory reliability of test scores. The corrected item-total correlations ranged between .45 and .72, indicating adequate homogeneity indices for all items (Table 3).

\section{Validity Evidence Based on Relationships with Other Variables}

GAIN scores were positively and significantly correlated with life satisfaction, and negatively and significantly correlated with caregiver burden, general mental health problems, stress, anxiety, and depression 
Table 1. Descriptive Statistics for Item Scores: Mean (M), standard deviation (SD), skewness, and kurtosis

\begin{tabular}{|c|c|c|c|c|c|}
\hline Items & $\begin{array}{l}\text { Providing care to my relative has... } \\
\text { [Cuidar a mi familiar me ha...] }\end{array}$ & $M$ & $S D$ & Skewness & Kurtosis \\
\hline 1 & $\begin{array}{l}\text { Helped to increase my patience and be a more understanding person } \\
\text { [Ayudado a tener más paciencia y ser más comprensivo/a] }\end{array}$ & 3.02 & 1.11 & $-1.15(0.23)$ & $0.83(0.45)$ \\
\hline 2 & $\begin{array}{l}\text { Made me a stronger and more resilient person } \\
\text { [Hecho más fuerte y resistente] }\end{array}$ & 3.20 & 0.98 & $-1.45(0.23)$ & $2.17(0.45)$ \\
\hline 3 & $\begin{array}{l}\text { Increased my self-awareness, making me more aware of myself } \\
\text { [Aumentado la conciencia de mí mismo/a, haciéndome más consciente de mí } \\
\text { mismo/a] }\end{array}$ & 3.08 & 0.98 & $-1.08(0.23)$ & $0.99(0.45)$ \\
\hline 4 & $\begin{array}{l}\text { Increased my knowledge and skills in dementia care } \\
\text { [Aumentado mis conocimientos y destrezas en el cuidado de enfermos con } \\
\text { demencia] }\end{array}$ & 3.34 & 0.86 & $-1.48(0.23)$ & $2.62(0.45)$ \\
\hline 5 & $\begin{array}{l}\text { Helped me grow closer to my relative with dementia } \\
\text { [Ayudado a sentirme más cerca de mi familiar con demencia] }\end{array}$ & 3.25 & 0.09 & $-1.02(0.23)$ & $0.79(0.45)$ \\
\hline 6 & $\begin{array}{l}\text { Helped to bond my family closer } \\
\text { [Ayudado a estrechar lazos con mi familia] }\end{array}$ & 2.62 & 1.26 & $-0.70(0.23)$ & $-0.33(0.45)$ \\
\hline 7 & $\begin{array}{l}\text { Enabled me to better relate to older persons and persons with dementia } \\
\text { [Permitido relacionarme mejor con personas mayores y personas con } \\
\text { demencia] }\end{array}$ & 3.02 & 1.03 & $-0.84(0.23)$ & $0.22(0.45)$ \\
\hline 8 & $\begin{array}{l}\text { Given me deeper insights into the meaning of life and my life's perspective } \\
\text { [Dado una visión más profunda sobre el significado de la vida y la } \\
\text { perspectiva de mi propia vida ] }\end{array}$ & 3.10 & 1.05 & $-1.37(0.23)$ & $1.77(0.45)$ \\
\hline 9 & $\begin{array}{l}\text { Helped me grow spiritually (e.g., closer to God and being able to look beyond } \\
\text { the material world) } \\
\text { [Ayudado a crecer espiritualmente (ej. más cercanía a Dios y ser capaz de ver } \\
\text { más allá del mundo material)] }\end{array}$ & 2.25 & 1.31 & $-0.30(0.23)$ & $-0.84(0.45)$ \\
\hline 10 & $\begin{array}{l}\text { Sparked off altruistic goals in me (e.g., wanting more to help others and } \\
\text { contribute to the welfare of others who may be going through similar } \\
\text { difficulties) [Despertado en mí el altruismo (ej., querer ayudar más a otros y } \\
\text { contribuir al bienestar de otros que pudieran estar pasando por } \\
\text { dificultades similares a las mías)] }\end{array}$ & 2.91 & 0.97 & $-0.42(0.23)$ & $-0.62(0.45)$ \\
\hline
\end{tabular}

Note. $N=113$.

Table 2. Fit Indices for the Single-factor Model of the GAIN, as Tested in the CFA

\begin{tabular}{lllllll}
\hline & $\chi^{2}$ & $\chi^{2}$ & $d f$ & CFI & NNFI & RMSEA (90\% CI) \\
\hline 1 factor & $1,450.44$ & 56.31 & 35 & .99 & .98 & $.07[.03, .10]$ \\
\hline
\end{tabular}

(Table 4). In terms of effect size, the associations between GAIN scores and burden, stress, depression, and life satisfaction were moderate, whereas the associations with general mental health problems and anxiety were of small magnitude.

\section{Interpretation of Scores}

The total score on the GAIN is obtained by summing the item scores (each scored from 0 to 4 ) and hence it ranges between 0 and 40, with higher scores indicating greater perceived gains from caregiving. In the present sample the minimum and maximum scores obtained were 8 and 40 , respectively, with a mean of $29.78(S D=7.17)$ and a median of 30. These are relatively high values and indicate that our participants generally perceive positive benefits associated with their caregiving role.

\section{Discussion}

The aim of this study was to analyze the psychometric properties of the GAIN in a sample of Spanish informal caregivers of persons with dementia. To this end, we began by conducting a CFA in order to obtain new validity evidence based on the internal structure of the instrument. We then analyzed the reliability of GAIN scores and examined item homogeneity. Finally, we sought to provide new validity evidence based on 


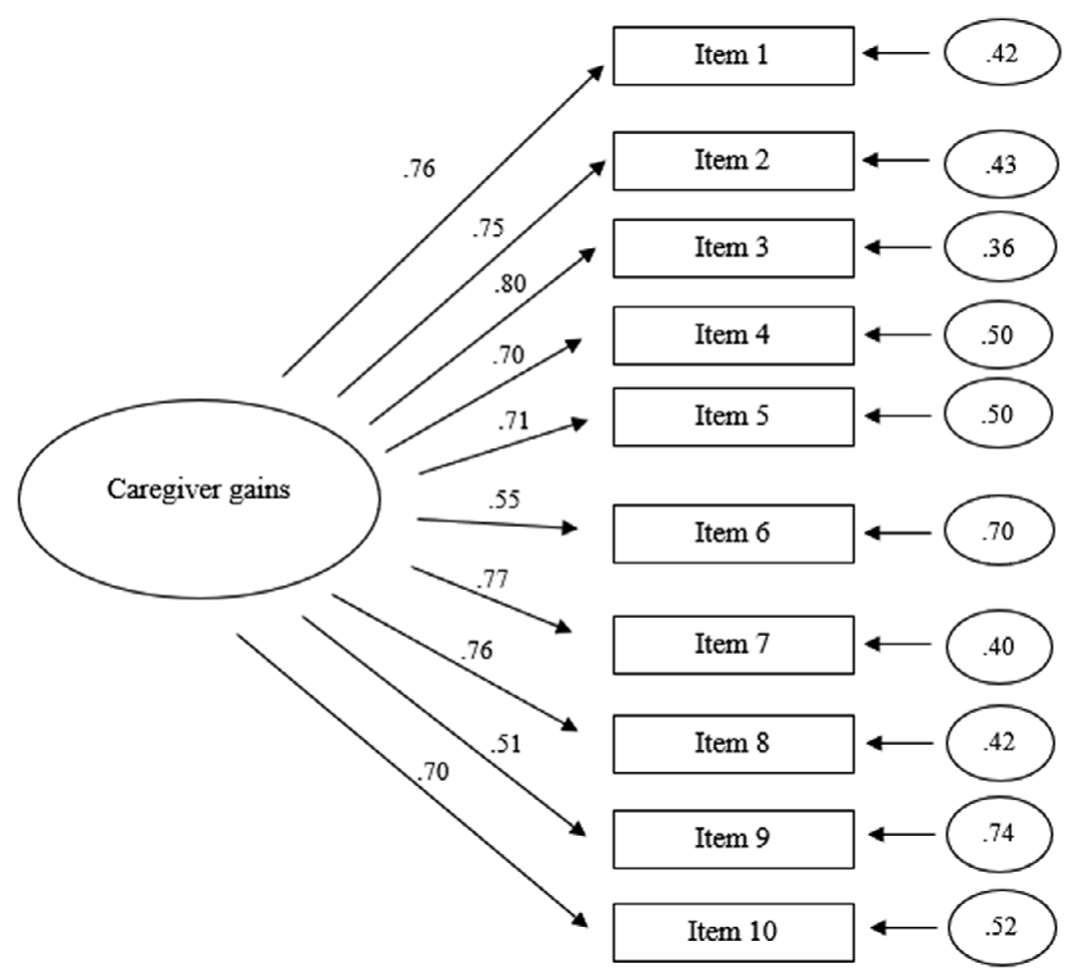

Figure 1. Single-factor model for the GAIN, with standardized parameter values.

Note. $\mathrm{N}=113 . \chi^{2}=$ chi-squared statistic, $\chi^{2 \mathrm{SB}}=$ Satorra-Bentler chi-squared, $\mathrm{df}=$ degrees of freedom, $\mathrm{CFI}=$ comparative fit index, NNFI = non-normed fit index, RMSEA = root mean square error of approximation, with a $90 \%$ confidence interval.

Table 3. Corrected Item-total Correlation Coefficients

\begin{tabular}{cc}
\hline Items & Corrected item-total correlation \\
\hline 1 & .65 \\
2 & .61 \\
3 & .70 \\
4 & .51 \\
5 & .61 \\
6 & .45 \\
7 & .72 \\
8 & .66 \\
9 & .53 \\
10 & .60 \\
\hline
\end{tabular}

Note. $N=113$.

relationships with other variables, specifically, caregiver burden, general mental health problems, stress, anxiety, depression, and life satisfaction.

The results of the CFA indicated that the GAIN has a single-factor structure. The fit indices were satisfactory, although the upper bound of the confidence interval for the RMSEA was above .08, suggesting that the model could be improved. However, as Kenny et al. (2015) point out, this index is highly sensitive to sample size and may be inflated with small samples, such as that
Table 4. Correlations between GAIN Scores and Caregiver Burden, General Mental Health Problems, Stress, Anxiety, Depression, and Life Satisfaction

\begin{tabular}{lc}
\hline Variables & Gains (GAIN) \\
\hline Burden (ZBI) & $-.38^{* *}$ \\
General mental health prob. (GHQ-12) & $-.20^{*}$ \\
Stress (DASS-21) & $-.38^{* *}$ \\
Anxiety (DASS-21 & $-.18^{*}$ \\
Depression (DASS-21) & $-.31^{* *}$ \\
Life satisfaction (SWLS) & $.30^{* *}$ \\
\hline
\end{tabular}

Note. $N=113$.

${ }^{*} p<.05 .{ }^{* *} p<.01$.

used in the present study. These authors therefore recommend using other indices such as the CFI or NNFI in models with few degrees of freedom. Based on the values obtained with the other fit indices we consider that the single-factor model shows a satisfactory fit to the data. This single-factor structure is consistent with that reported in previous studies, and as such the results of the CFA support those obtained through EFA (Fabà \& Villar, 2013; Yap et al., 2010). This structure also supports the use of the total test score, with higher scores indicating greater perceived benefits of caregiving. 
The results for item homogeneity and reliability based on internal consistency were also satisfactory. The value of McDonald's omega (.91) was similar to the alpha coefficient reported by Yap et al. (2010) for the original version of the instrument (.89) and to that obtained by Fabà and Villar (2013) when developing the Spanish adaptation of the GAIN (.87).

As regards validity evidence based on relationships with other psychological variables, the analysis showed that GAIN scores were positively and significantly correlated with life satisfaction and negatively and significantly correlated with caregiver burden, general mental health problems, stress, anxiety, and depression. Based on Cohen's (1988) criteria, most of these associations were of moderate magnitude, the exceptions being the small correlations obtained with respect to general mental health problems and anxiety. These results indicate that informal caregivers who perceive greater benefits from caregiving also report higher life satisfaction and lower levels of the following: Burden, general mental health problems, stress, anxiety, and depression. This is in line with previous studies which found that burden and mental health problems were negatively and significantly associated with caregiving gains (Liew et al., 2010; Yap et al., 2010), and it constitutes further empirical evidence of the relationship between GAIN scores and other measures of psychological wellbeing. Our findings are also consistent with those reported when using different instruments to measure caregiving gains, which likewise showed a positive relationship with life satisfaction and a negative association with depression and burden (Fabà et al., 2017). Overall, these results suggest that interventions aimed at enhancing the perceived gains of caregiving could have a positive impact on the caregiver's psychological health.

Despite providing new evidence for the validity and reliability of the GAIN, this study has a number of limitations that need to be acknowledged. First, all the data were obtained using self-report measures. Second, participants were recruited through day centers for people with dementia in the province of Malaga (southern Spain), which may limit the generalizability of results. Third, relationships between variables were examined using a correlational analysis, and hence no causality can be inferred. Finally, the sample size may be small, due to the difficulty of recruiting participants in settings such as this. Empirical evidence has shown that several factors affect sample size requirements, including number of indicators and factors, magnitude of factor loadings, and amount of missing data (Wolf et al., 2013). Overall, the analysis of complex models requires more sample size than that of a simpler model (Kline, 2011) as the one tested here. For example, Wolf et al. (2013) found that the eight-indicator single-factor model with loadings of .50 were associated with a minimum sample size of 90 . In any event, in order to extend knowledge, the present study should be replicated with larger samples in future research.

Although the GAC scale (Fabà et al., 2017) is also designed to measure gains associated with caregiving in the Spanish population, there are two reasons why we consider the GAIN to be a more suitable instrument overall. The first is that the GAC scale is focused on this population, whereas the GAIN is widely and internationally used, thus enabling cross-cultural comparisons. In addition, despite the important contribution of Fabà et al.'s (2017) study, further research is needed to clarify the internal structure of the GAC, whereas there is already empirical evidence from different cultural contexts supporting a clear structure for the GAIN.

In summary, we sought in this study to provide new validity evidence for the Spanish version of the GAIN, analyzing its psychometric properties in a sample of informal caregivers of people with dementia. We began by conducting a CFA to examine its internal structure, and then analyzed item homogeneity and the reliability of item scores. Finally, we explored the relationship between GAIN scores and other psychological variables, specifically, caregiver burden, general mental health problems, stress, anxiety, depression, and life satisfaction. The results obtained were satisfactory and indicated a good fit of the single-factor model to the data. Reliability of scores and item homogeneity were both satisfactory, and significant associations were found between GAIN scores and scores on all the other variables considered. The instrument is quick and easy to apply and given the association between GAIN scores and other variables, it may be used to provide information about a caregiver's psychological health status.

\section{References}

APA (2015). Influencia de las emociones positivas en la salud de los cuidadores de enfermos de Alzheimer [Influence of positive emotions on the health of Alzheimer caregivers] [Unpublished doctoral dissertation, Universitat de Vàlencia]. Repositori d'Objectes Digitals per a l'Ensenyament la Recerca i la Cultura.

Bentler, P. M. (1990). Comparative fit indexes in structural models. Psychological Bulletin, 107(2), 238-246. https: / / doi.org/10.1037/0033-2909.107.2.238

Bentler, P. M. (1992). On the fit of models to covariances and methodology to the Bulletin. Psychological Bulletin, 112(3), 400-404. http:/ / doi.org/10.1037/0033-2909.112.3.400

Bentler, P. M. (2006). EQS 6 Structural equations program manual. Multivariate Software, Inc.

Bentler, P. M., \& Bonett, D. G. (1980). Significance tests and goodness of fit in the analysis of covariance structures. Psychological Bulletin, 88(3), 588-606. https: / / doi.org/ 10.1037/0033-2909.88.3.588 
Browne, M. W., \& Cudeck, R. (1993). Alternative ways of assessing model fit. In K. A. Bollen \& J. S. Long (Eds.), Testing structural equation models (pp. 136-162). Sage.

Campo-Arias, A., \& Oviedo, H. C. (2008). Propiedades psicométricas de una escala: La consistencia interna [Psychometric properties of a scale: Internal consistency]. Revista de Salud Pública, 10, 831-839. http: / / doi.org/ 10.1590/S0124-00642008000500015

Cohen, C. A., Colantonio, A., \& Vernich, L. (2002). Positive aspects of caregiving: Rounding out the caregiver experience. International Journal of Geriatric Psychiatry, 17(2), 184-188. https:/ / doi.org/10.1002/gps.561

Cohen, J. (1988). Statistical power analysis for the behavioral sciences ( $2^{\text {nd }}$ Ed.). Lawrence Erlbaum Associates.

Daza, P., Novy, D. M., Stanley, M. A., \& Averill, P. (2002). The Depression Anxiety Stress Scale-21: Spanish translation and validation with a Hispanic sample. Journal of Psychopathology E Behavioral Assessment, 24, 195-205. https://doi.org/ 10.1023/A:1016014818163

del-Pino-Casado, R., \& Ordóñez-Urbano, C. (2016). Efectos de la satisfacción con el tiempo de ocio en personas cuidadoras de familiares mayores dependientes [Effects of satisfaction with leisure time on family carers of elderly dependents]. Atención Primaria, 48, 295-300. https: / / doi.org/10.1016/ j.aprim.2015.06.005

De Vaus, D. (2002). Analyzing social science data: 50 key problems in data analysis. Sage.

Diener, E., Emmons, R. A., Larsen, R. J., \& Griffin, S. (1985). The Satisfaction with Life Scale. Journal of Personality Assessment, 49(1), 71-75. https:/ / doi.org/10.1207/ s15327752jpa4901_13

Fabà, J., \& Villar, F. (2013). Ganancias asociadas al cuidado de personas con demencia: Adaptación al español de la escala GAIN [Gains associated with caring for people with dementia: A Spanish adaptation of the GAIN]. Revista Española de Geriatría y Gerontología, 48(3), 109-114. https: / / doi.org/10.1016/j.regg.2012.10.007

Fabà, J., Villar, F., \& Giuliani, M. F. (2017). Development of a measure to evaluate gains among Spanish dementia caregivers: The Gains Associated with Caregiving (GAC) Scale. Archives of Gerontology and Geriatrics, 68, 76-83. https:/ / doi.org/10.1016/j.archger.2016.09.004

Fowler, C. (2015). Cuidando del cuidador [Caring for the carer]. Nursing, 32(1), 34-37. https: / / doi.org/10.1016/ j.nursi.2015.02.009

Garson, G. D. (2015). Missing values analysis and data imputation. Statistical Associates Publishers.

Goldberg, D. P., \& Williams, P. (1988). A user's guide to the General Health Questionnaire. NFER-NELSON.

Hu, L., \& Bentler, P. M. (1999). Cutoff criteria for fit indexes in covariance structure analysis: Conventional criteria versus new alternatives. Structural Equation Modeling: A Multidisciplinary Journal, 6(1), 1-55. https:/ / doi.org/ $10.1080 / 10705519909540118$

Jöreskog, K., \& Sörbom, D. (2003). LISREL 8.54 [Computer software]. Scientific Software, Inc.

Kenny, D. A., Kaniskan, B., \& McCoach, D. B. (2015). The performance of RMSEA in models with small degrees of freedom. Sociological Methods \& Research, 44(3), 486-507. https:/ / doi.org/10.1177\%2F0049124114543236

Kline, R. B. (2011). Methodology in the Social Sciences. Principles and practice of structural equation modeling ( $3^{\text {rd }} \mathrm{Ed}$.). Guilford Press.

Kramer, B. J. (1997a). Gain in the caregiving experience: Where are we? What next? The Gerontologist, 37(2), 218-232. https: / / doi.org/10.1093/geront/37.2.218

Kramer, B. J. (1997b). Differential predictors of strain and gain among husbands caring for wives with dementia. The Gerontologist, 37(2), 239-249. https:/ / doi.org/10.1093/ geront/37.2.239

Liew, T. M., Luo, N., Ng, W. Y., Chionh, H. L., Goh, J., \& Yap, P. (2010). Predicting gains in dementia caregiving. Dementia and Geriatric Cognitive Disorders, 29(2), 115-122. https:/ / doi.org/10.1159/000275569

Lovibond, P. F., \& Lovibond, S. H. (1995a). Manual for the Depression Anxiety Stress Scales. Psychology Foundation of Australia.

Lovibond, P. F., \& Lovibond, S. H. (1995b). The structure of negative emotional states: Comparison of the Depression Anxiety Stress Scales (DASS) with the Beck Depression and Anxiety Inventories. Behavior Research and Therapy, 33, 335-343. https: / / doi.org/10.1016/0005-7967(94)00075-U

MacCallum, R. C., Browne, M. W., \& Sugawara, H. M. (1996). Power analysis and determination of sample size for covariance structure modeling. Psychological Methods, 1(2), 130-149. http:/ / doi.org/10.1037/1082-989X.1.2.130

Martín, M., Salvadó, I., Nadal, S., Miji, L. C., Rico, J. M., Lanz, P., \& Taussig, M. I. (1996). Adaptación para nuestro medio de la Escala de Sobrecarga del Cuidador (Caregiver Burden Interview) de Zarit [Spanish adaptation of the Zarit Burden Interview]. Revista de Gerontología, 6, 338-346.

McDonald, R. P., \& Ho, M.-H. R. (2002). Principles and practice in reporting structural equation analyses. Psychological Methods, 7(1), 64-82. https:/ / doi.org/10.1037/ 1082-989X.7.1.64

Netto, N. R., Jenny, G. Y. N., \& Philip, Y. L. K. (2009). Growing and gaining through caring for a loved one with dementia. Dementia, 8(2), 245-261. https: / / doi.org/10.1177\% 2F1471301209103269

Pearlin, L. I., Mullan, J. T., Semple, S. J., \& Skaf, M. M. (1990) Caregiving and the stress process: An overview of concepts and their measures. The Gerontologist, 30, 583-594. https: / / doi.org/10.1093/geront/30.5.583

Rapp, S. R., \& Chao, D. (2000). Appraisals of strain and of gain: Effects on psychological wellbeing of caregivers of dementia patients. Aging \& Mental Health, 4, 142-147. https: / / doi.org/ 10.1080/13607860050008664

Rocha, K. B., Pérez, K., Rodríguez-Sanz, M., Borrell, C., \& Obiols, J. E. (2011). Propiedades psicométricas y valores normativos del General Health Questionnaire (GHQ-12) en población general española [Psychometric properties and norms for the General Health Questionnaire (GHQ-12) in the Spanish general population]. International Journal of Clinical and Health Psychology, 11(1), 125-139.

Roepke, S. K., Allison, M., von Känel, R., Mausbach, B. T., Chattillion, E. A., Harmell, A. L., Patterson, T. L., Dimsdale, 
J. E., Mills, P. J., Ziegler, M. G., Ancoli-Israel, S., \& Grant, I. (2012). Relationship between chronic stress and carotid intima-media thickness (IMT) in elderly Alzheimer's disease caregivers. Stress, 15(2), 121-129. https: / / doi.org/10.3109/ 10253890.2011.596866

Sanders, S. (2005). Is the glass half empty or half full? Reflections on strain and gain in caregivers of individuals with Alzheimer's disease. Social Work in Health Care, 40(3), 57-73. https:/ / doi.org/10.1300/J010v40n03_04

Settineri, S., Rizzo, A., Liotta, M., \& Mento, C. (2014). Caregiver's burden and quality of life: Caring for physical and mental illness. International Journal of Psychological Research, 7 (1), 30-39. https: / / doi.org/10.21500/20112084.665

Steiger, J. H. (2000). Point estimation, hypothesis testing, and interval estimation using the RMSEA: Some comments and a reply to Hayduk and Glaser. Structural Equation Modeling, 7(2), 149-162. https: / / doi.org/10.1207/S15328007SEM0702_1

Traub, R. E. (1994). Reliability for the social sciences: Theory and applications. Sage.

Vázquez, C., Duque, A., \& Hervás, G. (2013). Satisfaction with Life Scale in a representative sample of Spanish adults: Validation and normative data. The Spanish Journal of Psychology, 16, E82. https://doi.org/10.1017/sjp.2013.82

Ventura-León, J. L., \& Caycho-Rodríguez, T. (2017). El coeficiente Omega: Un método alternativo para la estimación de la confiabilidad [The omega coefficient: An alternative method for estimating reliability]. Revista Latinoamericana de Ciencias Sociales, Niñez y Juventud, 15(1), 625-627.

Viladrich, C., Angulo-Brunet, A., \& Doval, E. (2017). Un viaje alrededor de alfa y omega para estimar la fiabilidad de consistencia interna [A journey around alpha and omega to estimate internal consistency reliability]. Anales de Psicología / Annals of Psychology, 33(3), 755-782. https: / / doi.org/ 10.6018/analesps.33.3.268401

Wolf, E. J., Harrington, K. M., Clark, S. L., \& Miller, M. W. (2013). Sample size requirements for structural equation models: An evaluation of power, bias, and solution propriety. Educational and Psychological Measurement, 73(6), 913-934. https: / / doi.org/10.1177\% 2F0013164413495237

Yap, P., Luo, N., Ng, W. Y., Chionh, H. L., Lim, J., \& Goh, J. (2010). Gain in Alzheimer care INstrument - A new scale to measure caregiving gains in dementia. The American Journal of Geriatric Psychiatry, 18(1), 68-76. https: / / doi.org/10.1097/ JGP.0b013e3181bd1dcd

Zarit, S. H., Reever, K. E., \& Bach-Peterson, J. (1980). Relatives of the impaired elderly: Correlates of feelings of burden. Gerontologist, 20, 649-655. https:/ / doi.org/10.1093/geront/ 20.6.649 